\title{
A Centralized Energy Coordinator Reliant on BESS and DER-PV Operation
}

\author{
Joseph M. Lavalliere, Elham B. Makram \\ Holcombe Department of Electrical and Computer Engineering, Clemson University, Clemson, USA \\ Email: jlavall@g.clemson.edu,makram@clemson.edu
}

Received 28 June 2016; accepted 5 August 2016; published 8 August 2016

Copyright @ 2016 by authors and Scientific Research Publishing Inc.

This work is licensed under the Creative Commons Attribution International License (CC BY).

http://creativecommons.org/licenses/by/4.0/

(c) (i) Open Access

\begin{abstract}
Many existing battery energy storage system (BESS) control schemes focus on mitigating negative impacts resulting from the operation of distributed energy resources-photovoltaic facilities (DERPV). These include out-of-firm conditions from reverse power flow or extreme variability in the service voltage. Existing control strategies fail to consider how BESS control schemes need to operate in a consecutive day-to-day basis in order for them to be implemented in the field. In this paper, a novel energy management algorithm capable of dispatching a BESS unit upstream of a multi-megawatt DER-PV is introduced. This algorithm referenced as the Master Energy Coordinator (MEC), accepts forecasted DER-PV generation and individual feeder load to create daily charge and discharge rate schedules. Logic is integrated to the cyclic discharging event to sync with the forecasted peak load, even when it will occur during the morning of the next day. To verify the MEC operation, Quasi-Static Time Series (QSTS) simulations are conducted on a $12.47 \mathrm{kV}$ distribution feeder model utilizing historical head-of-feeder and DER-PV analog DSCADA measurements.
\end{abstract}

\section{Keywords}

Energy Storage, Energy Dispatch Strategy, Solar Photovoltic Generation, Smart Grid

\section{Introduction}

Distribution Network Operators (DNOs) standard practice has been to operate with minimum monitoring and automation. For instance distribution substation circuit breaker statuses and analog measurements typically have resolutions of 1 - 2 s and 15 s - 15 m respectively [1]. Since On-Load Tap Changers (OLTCs) and Switch Capacitors typically operate based on local signals such as bus voltage, the voltage regulation is conducted in a noncoordinated manner. This methodology served DNOs well for many years until recently the significant increase in DER-PV inverter based multi-megawatt facilities. 
Today with IEEE standard 1547 restricting inverters in operating with near unity power factor [2], system voltage is more prone to reaching unacceptable levels. Implementation of digital control and sensing technologies will enable DNOs to combat the un-controllable nature of solar generation. In one instance, [3] proposed the integration of new digital control and sensing technologies to create a centralized coordination controller of distributed energy storage systems (DESS). Its objective was to relieve the operational stresses on the OLTC due to variable output of DER-PV facilities. When the regulator voltage deviated away from the bandwidth, distress signals were sent to all DESS to help mitigate reverse power flow and therefore directly impact feeder voltage. Another approach was proposed in [4] with a peer-to-peer multiagent (distributed) control technique. This enabled the DER-PV unit(s) to coordinate with the traditional utility regulation devices in two-way communication avenues. A decision maker was mapped from the construction of Input-Output logic of discrete point types and analog measures such as LTC/SVR voltage and DER reactive power injection level. The decision tables either requested a change in tap position or in inverter voltage and reactive power set points. The MEC was developed with the same concept that field devices were in communication locally with one another but instead under the assumption the DER-PV inverter set points could not be altered from either following IEEE 1547 or a customer owned asset. Instead, a locally connected DNO owned BESS is controlled to respond to a utility-scale DER-PV site located downstream with coordination between legacy devices.

\section{Master Energy Coordinator}

The primary objective for the proposed MEC is to adapt the BESS controller's charging and discharging schedules so that the asset will not be discharged to unnecessary levels. This will ensure the BESS is efficiency utilized and therefore directly extends its operational life. This centralized coordinator can be simply divided into three main functions, each contributing to proper coordination between voltage regulation devices and the BESS on a day-to-day basis. A simplified depiction of the MEC is provided in Figure 1. The primary function (MECF1) is to adjust the charging schedule based on known solar irradiance profiles and the BESS's estimated Depth of Discharge $(D o D)$ prior to a solar generation period. The secondary function (MEC-F2) is to perform a day-ahead lookout at the forecasted load and estimate when the peak will occur. The results will drive the tertiary function (MEC-F3) of determining if the BESS peak shaving controller should be enabled during the given day of operation or hold the BESS in idling mode until the consecutive day's morning peak is projected to occur.

MEC-F1 is driven from three inputs: the day-of-year's clear-sky irradiance (CSI) profile, the direct beam clear-sky irradiance $\left(B_{n c I}\right)$ profile, and the present $D o D$ during pre-daylight hours. The CSI and $B_{n c I}$ profiles with an example of both presented in Figure 2(b) are derived from the Ineichen \& Perez corrected Kasten Model accounting for DER-PV site location, site altitude, and derived solar azimuth and altitude angles [5]. The time at which the DER-PV will commence and cease generation $\left(T_{\mathrm{ON}} \& T_{\mathrm{OFF}}\right)$ can be estimated from referencing the CSI profile intersecting $10 \%$ of its peak. This threshold can be tuned dependent on the DNO's preference. The differences between these time instances formulate the extent of the BESS charging schedule (T). Assuming a constant charging schedule, the charge rate $\left(h_{1}\right)$ required to charge the BESS to $100 \%$ SoC can be found with Equation (1). The usable energy capacity for the upcoming cycle can be found by the initial $D o D$, with the BESS peak load shaving controller directly responsible for energy level. As presented in [6], a simultaneous solution of Equations ( $2 \& 3$ ) which model the total energy differentials from implementing a trapezoidal charge rate $(C R)$ profile is conducted to arrive at the Slope of Charge Rate $(S C R)$ and $h_{2}$ required to ensure $100 \%$ SoC. A SoC schedule was constructed directly from the CR profile $\left(C R_{r}\right)$ based on BESS energy capacity $\left(C_{B, \text { rated }}\right)$ and charging efficiency $\left(\eta_{C H}\right)$.

$$
\begin{gathered}
h_{1}=\left(C_{B, \text { rated }} \cdot \operatorname{DoD}(n)\right) \cdot T^{-1} \\
h_{2}^{2}+\left(2 \cdot h_{1}-T \cdot S C R\right) \cdot h_{2}+h_{1}^{2}=0 \\
\left(h_{1}+h_{1}\right) \cdot\left(T-2\left(h_{1}+h_{2}\right) \cdot S C R^{-1}\right)-\left(T o S_{2}+T_{o} S_{1}\right) \cdot C_{B, \text { rated }}=0
\end{gathered}
$$

The only remaining inputs to construct the $C R$ schedule profile are two $S o C$ thresholds $\left(T o S_{1} \& T o S_{2}\right.$ ). By procuring $5 \%$ of the available energy capacity for the $C R$ down-ramping period, $T o S_{2}$ is held constant at $95 \%$. Now, the shape of the $C R$ profile is solely dependent on $T o S_{1}$ which is the $S o C$ threshold representing the transition 


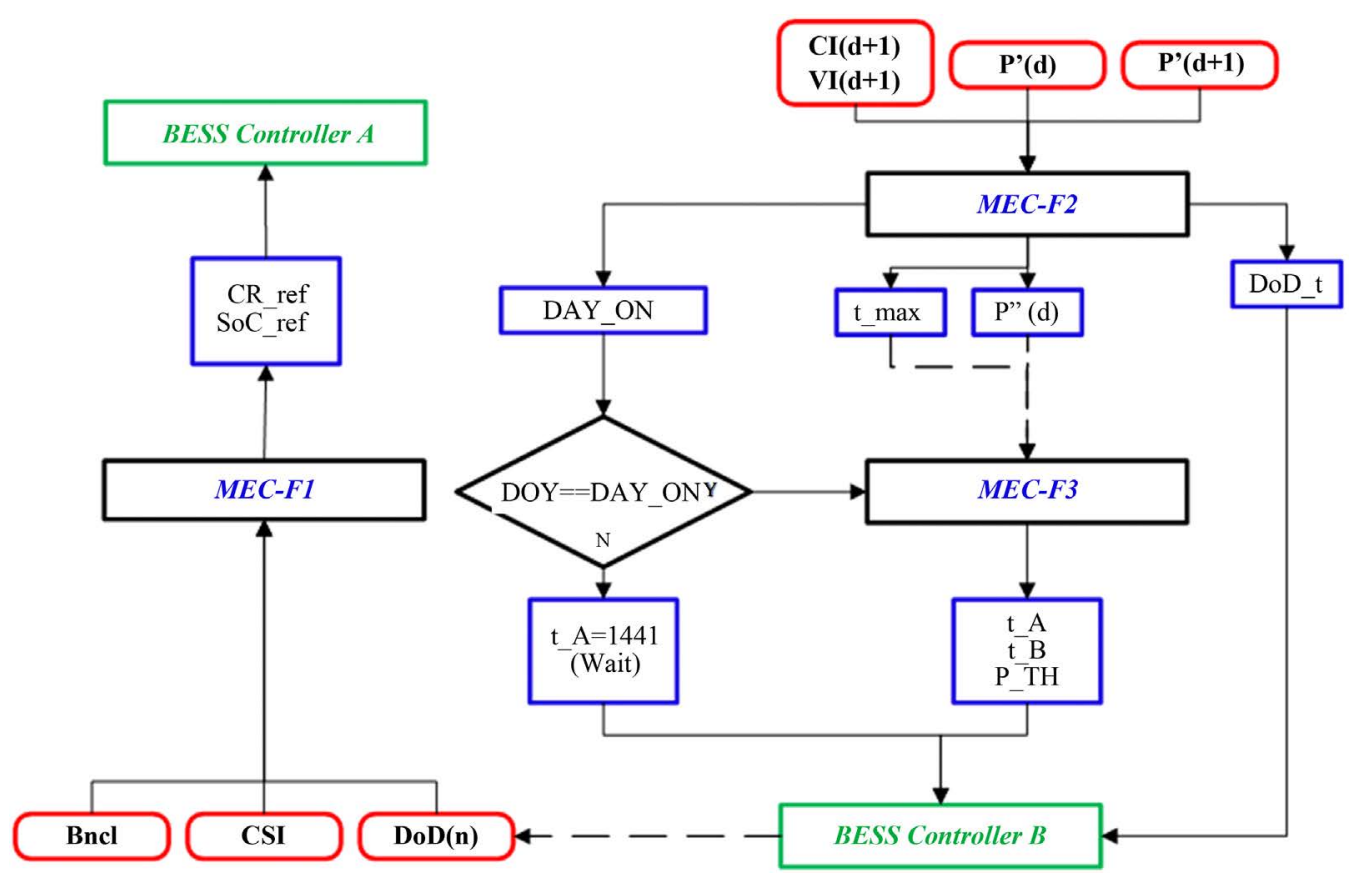

Figure 1. Master energy coordinator input/output scheme.

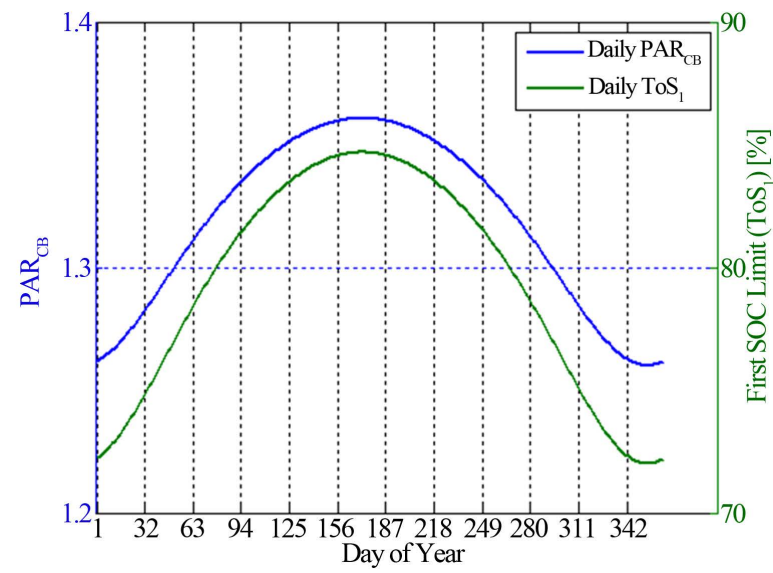

(a) Annual Projection of Controlled SoC Limit

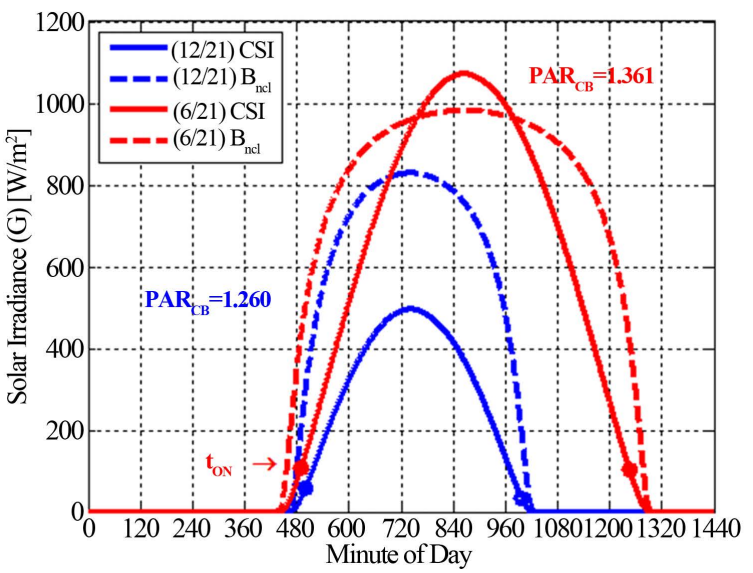

(b) Global and Direct Beam Clear-Sky Profiles

Figure 2. Adaption of the peak-to-average ratio between known CSI and $B_{n c I}$ profiles.

from a positive to zero slope. During the summer months, it is more probable that a DER-PV facility will generate for a longer extent of time. Therefore, $T o S_{1}$ can be tuned to this known fact by incorporating a discovered relationship between the CSI's and $B_{n c I}$ 's peak to average ratios $(P A R)$. With this model, the $C R$ schedule's trapezoidal shape will elongate to higher $C R$ levels with a higher $T o S_{1}$, capturing more energy during critical times. The ratio between the daily CSI and $B_{n c I}$ 's $P A R$ was calculated and presented in Figure 2(a). A sinusoidal pattern emerged with the minimum and maximum $P A R_{C B}$ occurring during the winter and summer solstice. The respected solar irradiance profiles are shown in Figure 2(b) to understand why this metric was drastically different.

The discovered pattern $P A R_{C B}$ was used as a means to adapt $T o S_{1} . P A R_{C B}$ converts to $T o S_{1}$ via Equation (4) by normalizing the profile with a base of $P A R_{C B \text {,min. }}$. To ensure the target $D o D$ will never violate the maximum $D o D$ of the BESS, Equation (5) is used to arrive at the positive offset for $T o S_{1}$.

$$
T o S_{1}=T o S_{1, \text { min }}+\left(P A R_{C B}-P A R_{C B, \min }\right) \cdot P A R_{C B, \min }
$$




$$
\operatorname{ToS}_{1, \min }=\left(1-D o D_{\text {max }}\right) \cdot\left(1+\left(1-\eta_{C H}\right)\right)
$$

It is important to note that the BESS charging controller will adapt to the variable nature of DER-PV, therefore the $S o C$ will deviate away from the schedule. If the pre-daylight $D o D$ is at a unnecessarily high level, the final SoC may not reach $100 \%$ especially during low irradiance days. Therefore, an additional forecasting needs to take place where the DER-PV's daily energy production is estimated based off of historical data and next-day Variability and Clear Sky Indices (VI and CI) [7]. To ensure the available energy capacity is fully utilized, MEC-F2 determines an ideal $D o D$ target $\left(D o D_{t}\right)$ to enforced during the BESS discharge mode of operation. Referencing forecasted feeder load, if the next day's peak load time is before 9 AM, then MEC-F2 transmits a flag to the connected BESS preventing discharge until the next day. This coordination will ensure the BESS will be used when it is needed most. If the peak load is projected to occur during the evening, MEC-F2 proceeds normally and the $D o D_{t}$ is estimated. To avoid unnecessary continuous discharge to the battery's maximum $D o D$, $D o D_{t}$ is set to a function of the upcoming day's solar generation daily energy yield estimate ( $\left.D E Y^{\prime}\right)$.

$$
D E Y_{n}^{\prime}=\hat{\beta}_{o}+\hat{\beta}_{1} \cdot V I+\hat{\beta}_{2} \cdot C I
$$

Equation (6) is a linear regression model to predict the next-day's DER-PV energy production with VI and $C I$ as the independent variables and a normalized $D E Y\left(D E Y_{n}\right)$ as the dependent variable. Utilizing annual historical DER-PV plant data, $D E Y_{n}$ was calculated on a daily basis with units of per-unit-hours (p.u.h.). Randomly selecting $90 \%$ of available daily historical VI, CI, and $D E Y_{n}$; a least squares regression analysis was conducted to arrive at the linear model's coefficients $\left(\hat{\beta}_{i}\right)$ as presented in Table 1 . The overall $\mathrm{R}^{2}$ of this regression model was found to be 0.8042 with residual standard error of 1.036 p.u.h. From these metrics, this model is sufficiently accurate in predicting the highly variable and chaotic daily DER-PV electric generation yield.

To convert the estimated $D E Y_{n}\left(D E Y_{n}\right.$ ') to $D o D_{t}$ for the peak load shaving controller, a piecewise linear function was implemented, as shown in Equation (7). This function is dependent on the BESS energy capacity $\left(C_{B, \text { rated }}\right)$, the BESS maximum depth of discharge $\left(D o D_{\max }\right)$, and the size of the DER-PV facility $\left(P_{P V \text {,rated }}\right)$. Since the BESS has a limited available energy capacity, a factor $(\alpha)$ was calculated by Equation (8) which references an annual average of observed $D E Y(D E Y)$. Equation (9) is a piecewise function that enforces a $D E Y^{\prime}$ limit to ensure that the $D o D_{t}^{\prime}$ will always be less than $D o D_{\max }$ during below-average solar generation days.

$$
\begin{gathered}
D o D_{t}=\left\{\begin{array}{c}
\alpha \cdot\left(\frac{D E Y_{n}^{\prime} \cdot P_{P V, \text { max }}}{C_{B, \text { rated }}}\right) \text { if }: D E Y_{n}^{\prime} \leq D E Y_{\alpha} \\
\left(D o D_{\text {max }}\right) \text { if }: D E Y_{n}^{\prime}>D E Y_{\alpha}
\end{array}\right. \\
\alpha=\frac{C_{B, \text { rated }}}{\overline{D E Y} \cdot P_{P V, \text { max }}} \\
\text { where: } D E Y_{\alpha}=\frac{D o D_{\text {max }} \cdot C_{B, \text { rated }}}{\alpha \cdot P_{P V, \text { max }}}
\end{gathered}
$$

To show the functionality of the MEC-F2, if a 12,121 kWh rated 33\% DoD and $1000 \mathrm{~kW}$ BESS is connected to a distribution feeder with the presence of a 3 MW DER-PV facility, the $\alpha$ would equal 0.2739 . The annual $\overline{D E Y}$ was found via historical DER-PV plant measurements which resulted in a $D E Y_{\alpha}$ of 4.886 p.u.h. With this model, if a $D E Y$ was predicted to be 3 p.u.h, the $D o D_{t}$ enforced on the BESS peak shaving controller would be $20.3 \%$. A static annual simulation of MEC-F2 was also conducted assuming an initial $100 \%$ SoC at each dispatch cycle. From this, it was observed that the maximum $D o D$ was reached more frequently during the summer

\begin{tabular}{ccccc}
\multicolumn{6}{l}{ Table 1. Prediction of normalized solar PV daily energy yield. } \\
\hline Coefficient & Value & Standard error & t-value & $\operatorname{Pr}(>|\mathrm{t}|)$ \\
\hline$\hat{\beta}_{o}$ & 0.4519 & 0.1427 & 3.167 & 0.00169 \\
$\hat{\beta}_{1}$ & 0.0135 & 0.0069 & 1.954 & 0.05153 \\
$\hat{\beta}_{2}$ & 7.2859 & 0.2101 & 34.67 & $<2 \mathrm{e}^{-16}$ \\
\hline
\end{tabular}


months and set extremely low target DoDs during the early winter months. These results illustrate MEC-F2 has the necessary processes to adapt the discharging cycle in preparation for the upcoming day's magnitude in DER-PV energy production.

The last process, MEC-F3, was designed to decide exactly when the BESS peak load shaving controller would be enabled and the power threshold to enforce. This decision is influenced by three inputs: time of the upcoming peak load $\left(t_{\max }\right)$ provided by MEC-F2, the forecasted feeder load shape, and an error threshold $(e)$ set to $0.1 \%$ or $10 \%$ of energy available. The overall process iteratively solves for the power threshold $\left(P_{T H}\right)$ necessary for peak load coverage and expenditure of available stored energy $\left(E_{B}\right)$ determined by Equation (10).

$$
E_{B}(n)=\operatorname{SOC}_{B}(n) \cdot C_{B, \text { rated }} \cdot D o D_{t}(n)
$$

The iteration process consists of first obtaining the power magnitude $\left(P^{\prime}\left(t_{A}\right)\right)$ at the peak loading period start time $\left(t_{A}\right)$. Then, the end time $\left(t_{B}\right)$ is increased at a 1 minute interval until either the projected difference in energy is within $10 \%$ of the available BESS energy or that the previous error is equal to the present error. In the later event, $t_{B}$ is reset and $t_{A}$ is moved back in time to arrive at a new power threshold. During the case when $t_{\max }$ is less than $540 \min (9 \mathrm{AM})$ and $t_{B}$ is greater than $630 \mathrm{~min}(10: 30 \mathrm{AM}), t_{B}$ is instead reset. With this implemented logic, an overlap between the discharge and charging period of the BESS will be prevented. The MEC-F3 algorithm continues until the projected expended energy is within $10 \%$ of the known available stored energy.

The coordination of MEC-F2 and MEC-F3 is evident in Figure 3 with a three day snapshot of a feeder load profile as well as the output from a connected 3 MW DER-PV facility shown in blue and green respectively. Initially MEC-F2 projected day \#2 to experience an evening peak. Therefore, the peak load shaving controller was enabled and MEC-F3 selected $t_{A}$ and $P_{T H}$. MEC-F2 also projected the DER-PV to be generating below average during day \#2. From this, the $D o D_{t}$ was set to $12.55 \%$.

Proceeding to day \#3, MEC-F2 projected a morning peak to occur. Therefore, the stored energy was held during the day \#2's evening peak. The magnitude of day \#3's $D o D_{t}$ almost doubled due to MEC-F2 predicting an increase in the daily DER-PV generation. This three-day benchmark only confirms the peak load shaving functionality of the MEC. In Section 3, MEC-F1 will be tested through a continuous QSTS simulation of the days shown in Figure 3. For demonstration purposes, historical DSCADA and irradiance measurements were

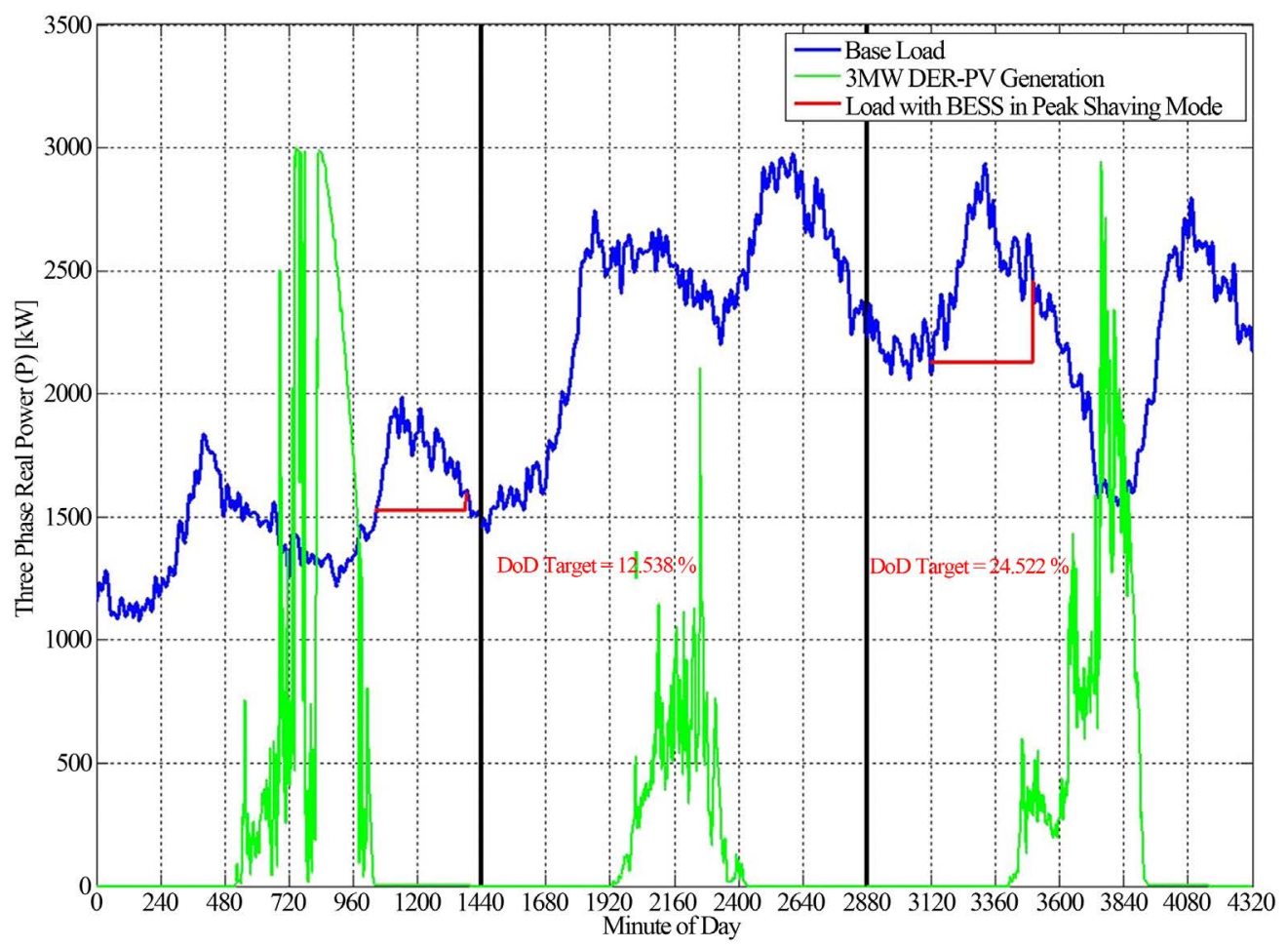

Figure 3. A three day snapshot (2/3 to 2/5) for interface testing between MEC-F2 and MEC-F3. 
substituted in for forecasted next-day feeder load and solar coefficients. DNOs do in fact have existing models which generate weather and load forecasts that can actually be integrated into real-time operations by leveraging an available Python library within the DNO’s distribution management system (DMS).

\section{Battery Energy Storage System Controller Logic}

The responsibility of the BESS Controller is to dispatch the battery's charging and discharging rates according to the current operational state of the distribution feeder. This controller can be divided into three main functions. The primary function of the BESS is to mitigate long term reverse power flow introduced by a downstream DER-PV facility. This is done by MEC-F1 providing a trapezoidal charge rate schedule following a known CSI profile. The secondary function is to respond to extreme short term DER-PV generation deviations, damping the feeder's power derivative by either providing power during a loss-of-generation event or consuming power during a fast gain-of-generation event. The third function is to implement peak load shaving during a desired time and limit, both provided by MEC-F3. The first two functions are incorporated into Controller "A" with the other into Controller "B". Logic is built to select which controller should be enabled based if the DER-PV facility is generating above a certain threshold or if the time of operation is with the peak shaving window. The overall BESS controller adapts to select feedback from the field including the DER-PV real power measurements and head-of-feeder OLTC Boolean flags signifying if a high voltage or low voltage event is being experienced.

The internal logic of Controller "A" is presented in Figure 4. The CR or temporary DR during DER-PV operation is amplified by a change of rate (COR) factor. When the OLTC is experiencing a violation, the BESS controller defines the COR gain to $125 \%$. A larger COR will force the BESS to respond quicker to an OLTC voltage violation event. When referencing the logic, setting the $A 1$ and $A 2$ variables (shown in green) to either a positive, negative, or null value directly impact the magnitude of either a CR or DR response. During real-time operation Controller "A" dispatches a new CR/DR command every 5 seconds; responding to either a rapid loss or gain in DER-PV generation, attempting to reach scheduled SoC, or following schedule CR.

Experiencing extreme deviations in DER-PV output is a widely known fact in the power systems industry and can drastically impact the operation of voltage regulation equipment. Hence, this operational case was positioned as priority. The BESS Controller " $A$ " accepts field measurements from the DER-PV facility and internally calculates the power deviation at each five second dispatch interval. A predefined deviation threshold $\left(P_{T H}\right)$ was selected to be $0.01 \mathrm{~kW} / 5$ sec based on analyzing historical PV plant output. Each day was classified by its VI and CI according to SNL's Classification Scheme [8]. When enforcing a $P_{T H}$ of $0.01 \mathrm{kw} / 5 \mathrm{sec}$, previous

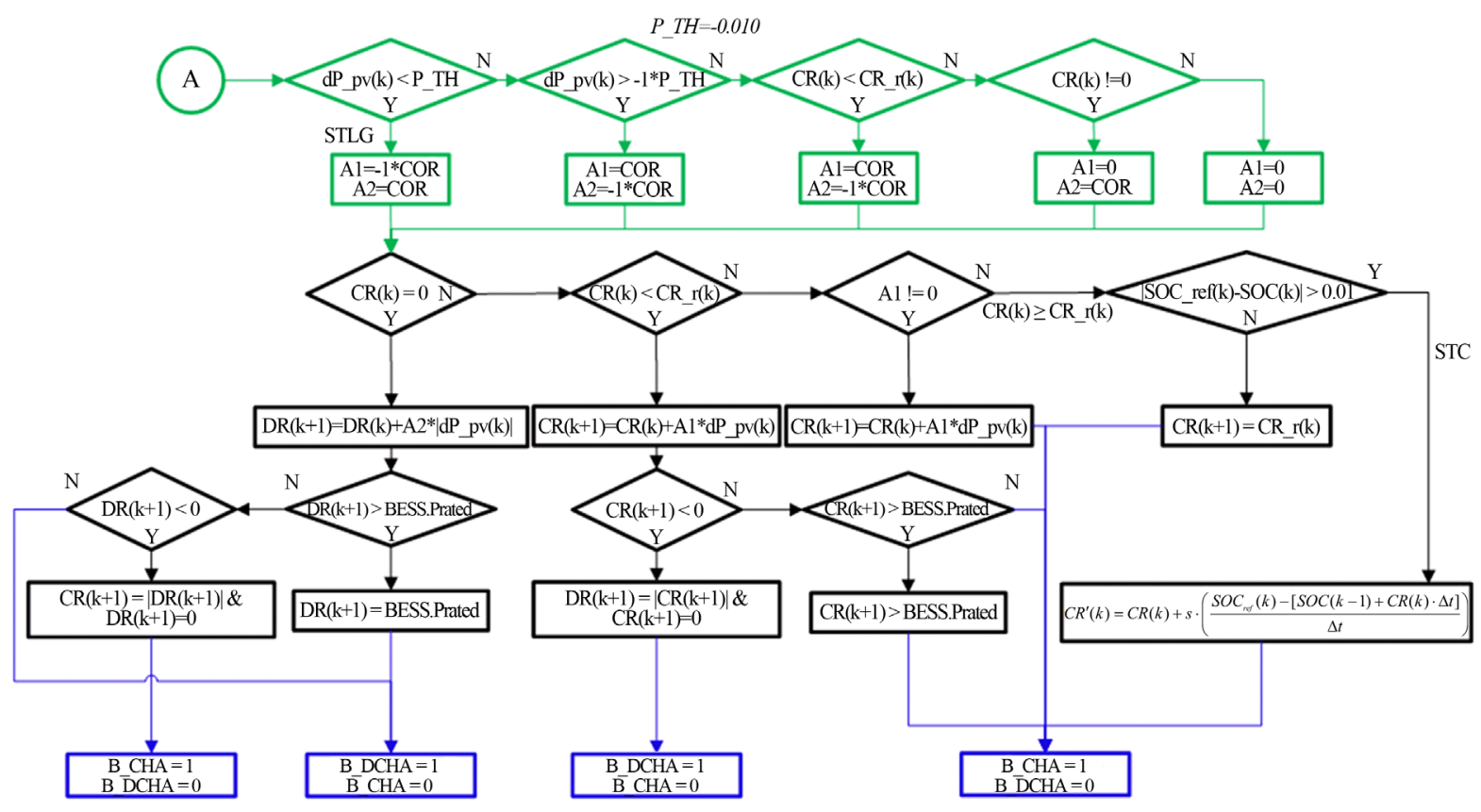

Figure 4. A BESS controller "A" that is enabled during solar PV generation. 
DER-PV power deviations would cause a violation $2 \%$ of possible dispatch intervals. This translates into approximately 101 hours out of the year when an extreme power deviation event would force a response from the BESS controller. Note that $\mathrm{P}_{\mathrm{TH}}$ will require tuning if the controller is applied to a different facility because power deviations can depend on the PV system's size, orientation, configuration, and location.

In the event that an observed derivative is negative and less than- $P_{T H}$, then it was assumed the DER-PV was experiencing an extreme decrease in generation. Acceleration gains ( $A 1$ or $A 2)$ are applied to the observed PV derivative and either added to $C R(k)$ or subtracted from $D R(k)$ as shown in Equation (11). If this event extends for a long period of time, then there is a chance the controller will switch to short term discharging mode [6] when the BESS becomes a generator and injects power. After when the DER-PV's generation finally begins to ramp up, the derivative becomes positive. In this situation, the same acceleration gains will be used except opposite in sign. If the BESS is in discharging mode during this time, Equation (12) is applied to gradually decrease the magnitude of the $D R$. If the next dispatched $D R$ is determined to be less than zero, then the BESS reverses to charging mode and sets the $C R$ equal to the recently determined $D R$, thus consuming power again.

$$
\begin{gathered}
C R(k+1)=C R(k)+A 1 \cdot\left|d P_{P V}(k)\right| \\
D R(k+1)=D R(k)+A 2 \cdot\left|d P_{P V}(k)\right| \\
C R(k+1)=C R(k)+\left(S O C_{\text {ref }}(k)-[S O C(k-1)+C R(k) \cdot \Delta t]\right) \cdot \Delta t^{-1}
\end{gathered}
$$

Onto the second situation when the DER-PV power deviation does not violate the threshold and the BESS $\mathrm{SoC}$ is below the $S o C$ schedule, the CR will be adjusted by a factor determined by Equation (13) [6]. This will continue until the $S o C$ is again within $1 \%$ of the scheduled level. During extremely variable days, a situation can arise when the required CR to bring the battery's SoC back up to the schedule surpasses the rating of the BESS. Therefore, a limiter is enforced so that the CR saturates at the rated $\mathrm{kW}$. The third situation is when the BESS operates under normal conditions with minimal power deviations or the $S o C$ is within the $1 \%$ threshold. In such a situation, the BESS will follow the charge rate schedule produced by MEC-F1. Also, Controller "B" can become priority during this time if the DER-PV is generating below a set limit and after $t_{A}$.

\section{Consecutive Three-Day Operation of the Proposed M.E.C.}

In order for the centralized MEC to possibly become integrated into a DER Management and Forecasting DMS environment, multiple simulations are required in order to observe the decisions and resulting operations of the OLTC, Switch Capacitor, and BESS. Referencing [9], an advanced Lead Acid Battery bank was selected with a $1000 \mathrm{~kW}$ rated output and a total energy capacity of $12,121 \mathrm{kWh}$. With a maximum $D o D$ of $33 \%$, the roundtrip efficiency was assumed to be $90 \%$ with a total plant cost of approximately $\$ 4.855$ million. Typically, the BESS has a controllable power converter to condition DC voltage into an AC synchronized waveform which is then connected in series to a $480 \mathrm{~V} / 12 \mathrm{kV}$ step-up transformer [9]. Using load and DER-PV generation profiles visualized in Figure 3, the QSTS simulation architecture was built with Open DSS as the power flow engine and applied to the actual $12.47 \mathrm{kV}$ distribution feeder model with the DER's point of interconnections in Figure 5.

Due to the robustness in logic, the MEC can sustain the BESS in cyclic operation over consecutive days by intelligently controlling the energy capacity available at the start of each DER-PV charging period/day. To illustrate this, a three day consecutive QSTS simulation was conducted with results found in Figure 6. Three cases were compared to fully illustrate the benefits of implementing the MEC including a base case without any DERs, a 3 MW DER-PV in operation, and finally with the DER-PV and BESS in operation.

Day \#1 provided an above average DER-PV energy yield while days \#2 and \#3 experienced below average DEYs. Referencing Figure 6(a), note MEC-F2 and MEC-F3 functioned properly, holding the stored energy during day \#2 and commencing in peak load shaving during the evening and morning periods of days \#1 and \#3 respectively. Observing Figure 6(c), the BESS successfully charged to the target SoC on days \#1 and \#3 but 2\% below the schedule during day \#2. Since this day was categorized as overcast, the DER-PV plunged below the $10 \%$ nameplate threshold before the scheduled charging period was complete. Inspecting Figure 6(d), the BESS's CR and DR provide insight into the asset's dispatch history throughout the variable DER-PV generation window and peak load shaving operation. During the solar generation hours, the blue line which represents the 


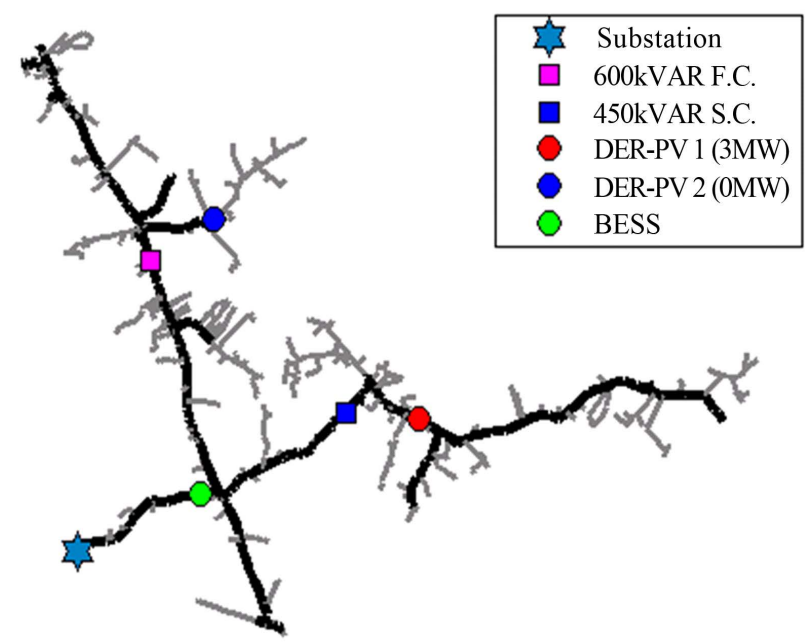

Figure 5. Test feeder topology and component locations.

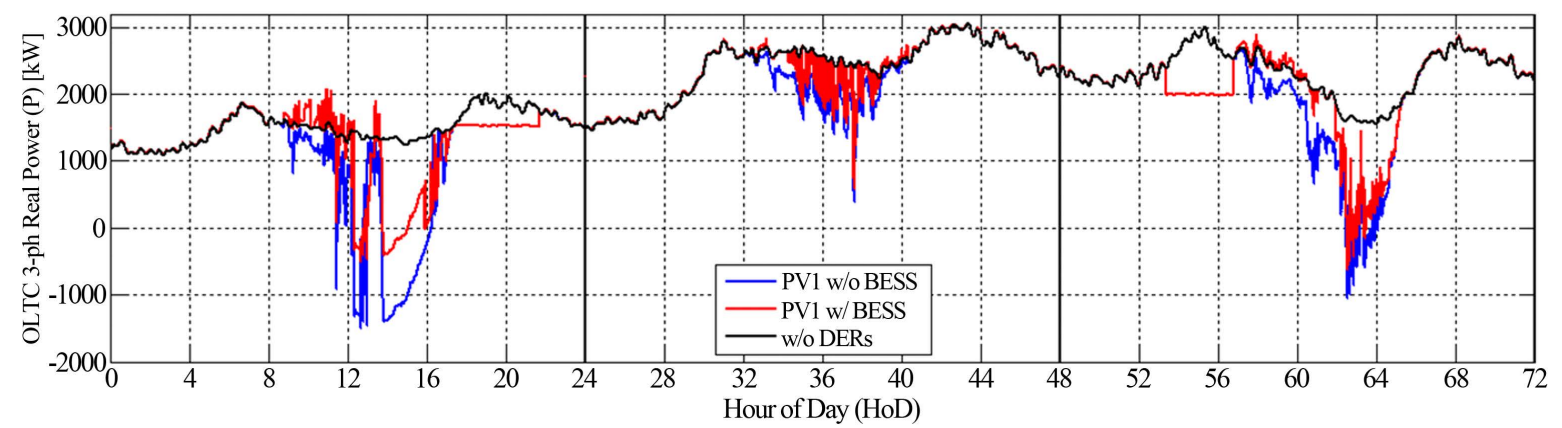

(a)

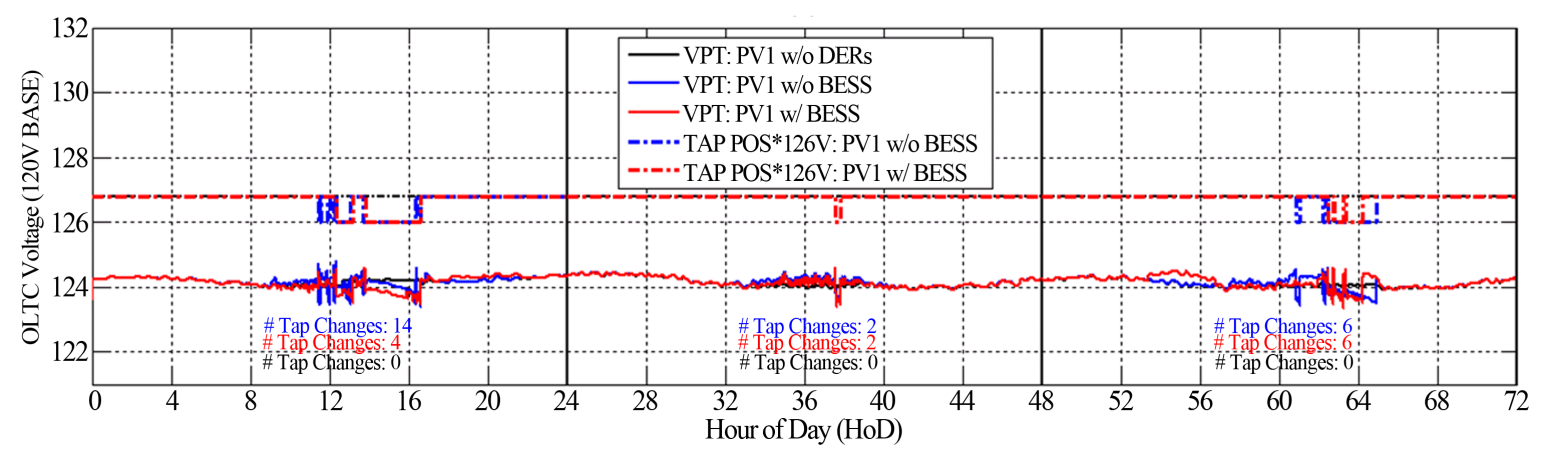

(b)

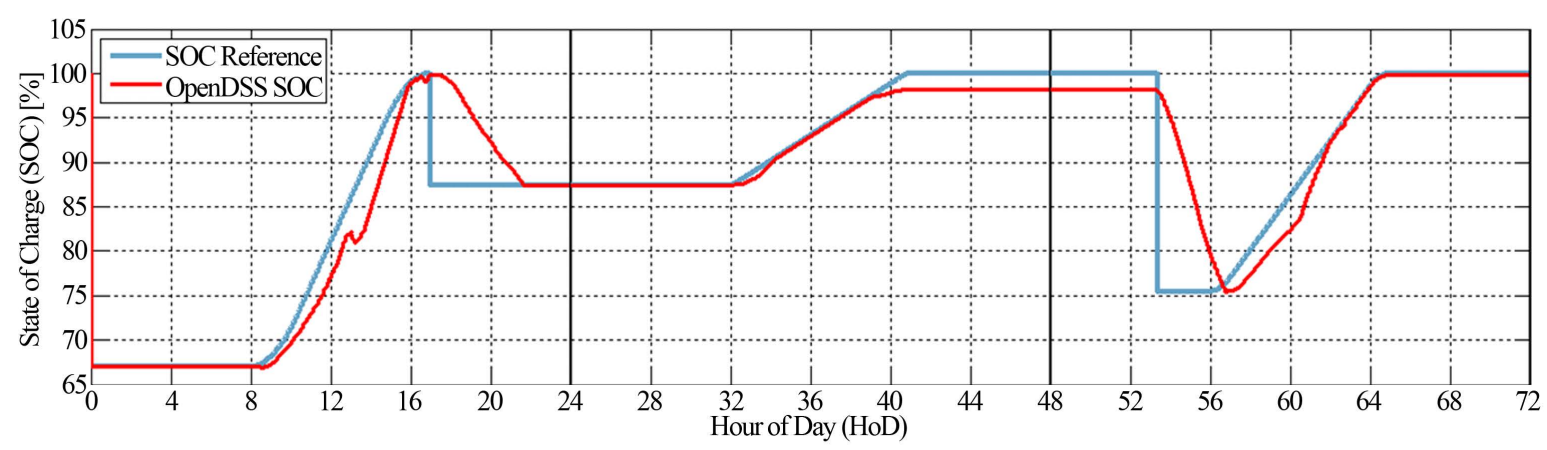

(c) 


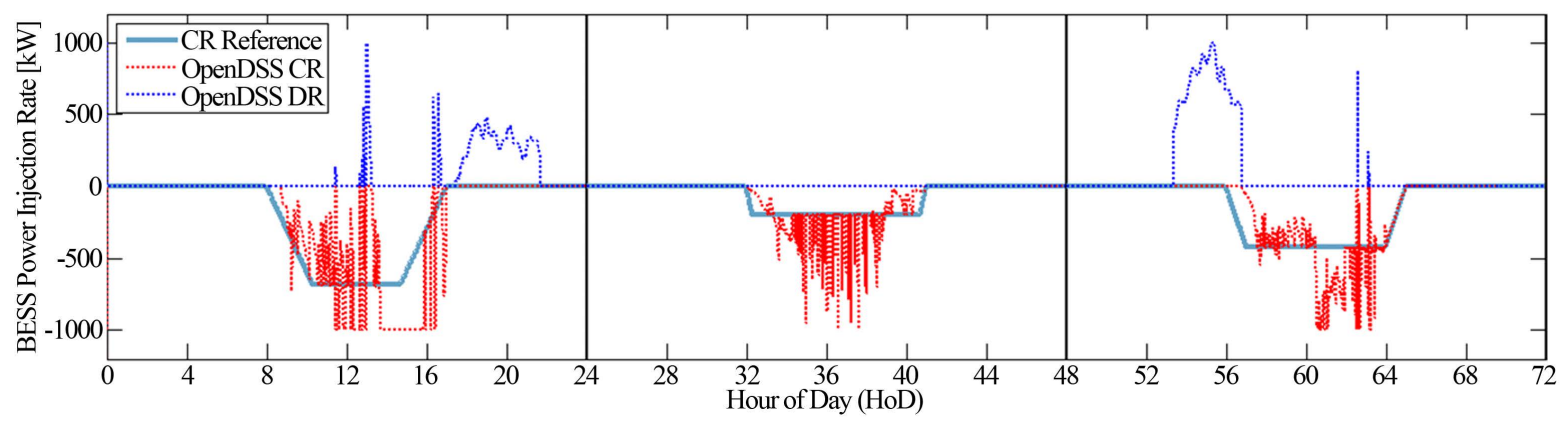

(d)

Figure 6. Open DSS results of a consecutive three day run.

BESS's DR spiked at certain times when there was an extreme loss in generation. This was Controller "A" attempting to dampen the voltage variability by injecting power as needed. When referencing Figure 6(b), the positive impact of this action can be seen when the number of additional tap change decreased from 14 to 4 . From these results, installing a BESS at the distribution voltage level will increase the control system operators have to combat guaranteed extreme ramping of conventional generation during the morning or evening transition periods equivalent to the one illustrated in the CAISO "duck curve" [9].

\section{Conclusions}

With the increasing use of renewable energy sources, the power grid is reaching a significant penetration level. DNOs and ISOs will require an additional sensing/monitoring, control, and protection. Advanced two-way communication between controllable network devices will facilitate Advanced Distribution Automation necessary when implementing DER management and forecasting control algorithms such as the proposed Master Energy Coordinator. Dispersing battery energy storage systems on the individual distribution feeder level is just one possible solution to mitigate the adverse operational tap changer stresses and OOF voltage conditions with DER-PV generation. If inverter standards are revised to allow participation in voltage regulation, the need for a DER management system (DERMS) will be even more prominent. A DERMS platform will need to be capable of accepting numerous field measurement points and dispatching commands to all controllable equipment such as automatic switches, OLTC/SVRs, SCs, BESSs, and DER-PV inverters [10].

In conclusion, the Master Energy Coordinator coherently establishes and enforces when a feeder-connected BESS should charge during DER-PV's generation window and when it should discharge during the distribution network's peak loading condition. This coordination scheme and associated equipment controllers fulfilled the three main proposed goals. The first goal is mitigating reverse power flow and long-term high voltage events. The second goal is decreasing the additional operational stress on the OLTCs by dampening the extreme shortterm generation ramp rates. The third and last goal is discharging the captured energy during the most cost effective times. Grid modernization initiatives that implement new digital technology to traditional power system equipment allow automated solutions such as MEC to become a reality. Thus, in order for distribution systems to host vast amounts of renewable generation, it is essential that the existing DNO platform management systems migrate to incorporate advanced DER coordination techniques.

\section{Acknowledgements}

The authors would like to thank the members of the Center of Advanced Power Engineering Research (CAPER) and the Clemson University Electric Power Research Association (CUEPRA) for their financial support. Authors would also like to thank Duke Energy distribution group for their valuable discussion and for providing system models with associated historical data.

\section{References}

[1] Thomas, M.S. and McDonald, J.D. (2015) Power System SCADA and Smart Grids. CRC Press, Taylor \& Francis Group, Boca Raton. 
[2] (2014) IEEE Standard for Interconnecting Distributed Resources with Electric Power Systems-Amendment 1. IEEE Std 1547a-2014 (Amendment to IEEE Std 1547-2003), 1-16.

[3] Liu, X., Aichhorn, A., Liu, L. and Li, H. (2012) Coordinated Control of Distributed Energy Storage System with Tap Changer Transformers for Voltage Rise Mitigation Under High Photovoltaic Penetration. IEEE Transactions on Smart Grid, 3, 897-906. http://dx.doi.org/10.1109/TSG.2011.2177501

[4] Farag, H.E., El-Saadany, E.F. and Seethapathy, R. (2012) A Two Ways Communication-Based Distributed Control for Voltage Regulation in Smart Distribution Feeders. IEEE Transactions on Smart Grid, 3, 271-281. http://dx.doi.org/10.1109/TSG.2011.2167355

[5] Ineichen, P. and Perez, R. (2002) A New Airmass Independent Formulation for the Linke Turbidity Coefficient. Solar Energy, 73, 151-157. http://dx.doi.org/10.1016/S0038-092X(02)00045-2

[6] Alam, M.J.E., Muttaqi, K.M. and Sutanto, D. (2013) Mitigation of Rooftop Solar PV Impacts and Evening Peak Support by Managing Available Capacity of Distributed Energy Storage Systems. IEEE Transactions on Power Systems, 28, 3874-3884. http://dx.doi.org/10.1109/TPWRS.2013.2259269

[7] Stein, J.S., Hansen, C.W. and Reno, M.J. (2012) The Variability Index: A New and Novel Metric for Quantifying Irradiance and PV Output Variability. World Renewable Energy Forum, Denver.

[8] EPRI (2015) Alternatives to the 15\% Rule: Final Project Summary. Report No. 3002006594, Electric Power Research Institute, Palo Alto. http://www.epri.com/Pages/Default.aspx

[9] Akhil, A.A., Huff, G., Currier, A.B., Kaun, B.C., Rastler, D.M., Chen, S.B., et al. (2013) DOE/EPRI 2013 Electricity Storage Handbook in Collaboration with NRECA. Sandia National Laboratories (SNL). Albuquerque, NM..

[10] Denholm, P., O’Connell, M., Brinkman, G. and Jorgenson, J. (2015) Overgeneration from Solar Energy in California: A Field Guide to the Duck Chart. Sandia National Laboratories (SNL). Golden, CO.

http://www.sandia.gov/

http://dx.doi.org/10.2172/1226167

\section{Submit or recommend next manuscript to SCIRP and we will provide best service for you:}

Accepting pre-submission inquiries through Email, Facebook, LinkedIn, Twitter, etc.

A wide selection of journals (inclusive of 9 subjects, more than 200 journals)

Providing 24-hour high-quality service

User-friendly online submission system

Fair and swift peer-review system

Efficient typesetting and proofreading procedure

Display of the result of downloads and visits, as well as the number of cited articles

Maximum dissemination of your research work

Submit your manuscript at: http://papersubmission.scirp.org/ 